\title{
EDUCAÇÃO POPULAR, SAÚDE, EQUIDADE E JUSTIÇA SOCIAL
}

\author{
Miguel G. Arroyo*
}

\begin{abstract}
RESUMO: O processo de desconstrução de imaginários negativos, de reconhecimento de autoimagens pelo próprio povo e de construção de imagens positivas tem sido um dos aspectos mais pedagógicos do movimento de educação popular. Nesse processo vão se conformando o pensamento e as intervenções práticas da educação popular e saúde. Expõem-se algumas visões persistentes e resistentes sobre povo: visões naturalizadas, biologizadas, patológicas; de carentes sociais a desqualificados morais. O artigo discute os vínculos entre educação popular e saúde, equidade e justiça social, na intenção de revelar a sensibilidade da educação popular e saúde para este novo momento político posto na cena política pelos setores populares organizados.
\end{abstract}

Palavras-chave: Educação popular. Saúde popular. Movimentos sociais.

\section{POPUlAR EDUCATION, HEALTH AND SOCIAL JUSTICE}

ABSTRACT: Having the very people deconstruct negative imaginaries, self-image recognition to build positive images has been one of the most pedagogical aspects of the popular education movement. Such process conforms the thinking and practical interventions of popular education and health. This paper presents some persistent and resistant visions on the people: naturalized, biologized, pathological visions that see them from socially needy to morally disqualified persons. This text discusses the links between popular education and health, equity and social justice in order to reveal the sensitivity of popular education and

Doutor em Educação e professor titular emérito da Faculdade de Educação da Universidade Federal de Minas Gerais (UfMG).E-mail: g.arroyo@uol.com.br 
health for this new political times introduced in the political arena by organized popular sectors.

Key words: Popular education. Popular health. Social movements.

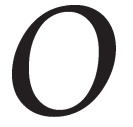

s vínculos entre educação e saúde e os setores populares têm se pautado ora pelas tentativas de revelar as verdades do povo, ora pelo confronto com as visóes com que tem sido visto o povo em nossa cultura política.

O movimento de educação popular, desde suas origens no Brasil, nos anos de 1960 , e mais tarde o movimento de saúde popular se propóem a tirar o povo do silenciamento e ocultamento a que estava submetido nas ciências sociais, na cultura política e também no pensamento educacional e de saúde. Propóem-se a revelar as funções políticas e antipedagógicas deste ocultamento: negar o povo como sujeito político e cultural, mantê-lo à margem, decretando a sua não-existência política e cultural e reduzindo-o a braços para os trabalhos mais desqualificados e para a saúde e sobrevivência nos limites.

O movimento de educação popular se propõe, ainda, outra tarefa: desconstruir os imaginários sociais negativos sobre o povo e mostrar sua inconsistência. Contrapõe-se a estes imaginários, mostrando sua função política, segregadora. Uma forma perversa de silenciamento e marginalização tem sido nomeá-lo através da diversidade de metáforas e imagens negativas e depreciativas do povo, que tentaram inferiorizálo a ponto de não ter sentido político e cultural reconhecê-lo. Ora são destacadas umas representações do povo, ora outras, mas se mantém uma persistência de significados negativos.

O movimento de educação popular mostra que o ocultamento é apenas aparente. $\mathrm{O}$ povo foi reconhecido, porém no lugar-sem lugar que lhe foi reservado no padrão de classificação sociorracial: no pólo da ignorância, da tradição, do primitivismo, da irracionalidade, da imaturidade e minoridade. As metáforas sobre o povo revelam este lugarnão lugar que lhe foi reservado.

A história da educação popular é reveladora desta diversidade de metáforas e representaçóes sobre o povo que se sucedem e se reforçam em nossa cultura política e até pedagógica e de saúde. Entretanto, o movimento de educação popular avança tentando revelar outros 
imaginários positivos que tornem os setores populares mais visíveis e acreditados. A este movimento se deve a produção de outras imagens mais positivas.

Há outro dado a incluir nestas relações entre educação popular, saúde e os setores populares: as autoimagens que o povo vai mostrando de si mesmo à sociedade e que o movimento de educação popular vai captando, revelando e afirmando em contraposição às imagens dominantes do povo na cultura política. Ao longo destas décadas, os coletivos populares vão entrando na cena política e cultural e revelando suas verdades e autoimagens.

Este processo de desconstrução de imaginários negativos, de reconhecimento de autoimagens pelo próprio povo e de construção de imagens positivas tem sido um dos aspectos mais pedagógicos do movimento de educação popular.

Nestes processos de detectar, denunciar, desconstruir imaginários negativos e de afirmar imagens positivas do povo, vão se conformando o pensamento e as intervenções práticas da educação popular e saúde. Por exemplo: como reação à visão tão negativa do povo como ignorante, inculto, selvagem, atrasado, a educação popular destaca os saberes e a cultura deste povo.

Ao longo de várias décadas de história da educação popular, podemos perceber ênfases diferentes nos vínculos entre educação, saúde e setores populares. $\mathrm{O}$ tema deste artigo nos propóe a vincular educação popular e saúde com a equidade e justiça social. Por que destacar estes vínculos novos? Onde encontrar estes vínculos? Estes respondem a novos imaginários sobre o povo? A hipótese que poderia nos guiar é de que estamos em um momento político de especial tensão entre as imagens sociais dominantes sobre o povo e as autoimagens que os movimentos sociais populares vêm construindo sobre si mesmos. Privilegiar os vínculos entre educação popular e saúde, equidade e justiça social revelará a sensibilidade da educação popular e saúde para este novo momento posto na cena política pelos setores populares organizados.

\section{O imaginário do povo na cultura política}

Para entender o tema e situá-lo no momento atual, será interessante fazer pesquisas que reconstruam a história da educação popular a 
partir das imagens do povo que são dominantes em cada tempo, em nossa cultura política. Reconstruir como o movimento de educação popular e saúde reage a estas imagens e à realidade que elas sugerem, criando outras imagens para revelar outras realidades e verdades sobre o povo. Quando o movimento de saúde popular se aproxima da educação popular, ambos se tornam parceiros destes processos: detectar as imagens e metáforas sobre o povo, tão marcantes em nossa cultura política, denunciar o que elas ocultam e desvirtuam e se contrapor a esta visão através de outras imagens e metáforas que revelem o povo real; ver nesta história um fazer pedagógico da maior importância; pesquisar como o movimento de educação popular e saúde reeduca nossa cultura política e denuncia as visôes estereotipadas, persistentes em relação ao povo. Poderia ser feita uma pesquisa sobre como as metáforas, os nomes e adjetivos que são usuais representam sínteses de significados e de formas de pensar e tratar os setores populares.

A contraposição que o movimento de educação popular e saúde faz a estas visôes provoca um processo político pedagógico de confronto de significados. A dimensão pedagógica desta contraposição passa por conformar outros modos de pensar e atuar com os setores populares. Porém, não será suficiente que os educadores que trabalham junto aos setores populares se libertem de imagens estereotipadas, será necessário que a cultura política seja confrontada, desestabilizada e que os próprios setores populares se libertem destas imagens que, ao longo da nossa história, pesam sobre eles. Até onde esta tarefa foi cumprida?

As imagens com que nossa cultura política e também as ciências e mesmo os profissionais que trabalham com o povo por vezes compartilham (profissionais da educação, da saúde, do direito, da ação social...) se mantiveram persistentes. Seria importante pesquisar em que medida estas imagens persistem e resistem para denunciá-las, desconstruí-las, ao menos em nossos imaginários e tratos com o povo. Tentemos identificar algumas destas imagens persistentes e resistentes.

\section{Visões naturalizadas, biologizadas e patológicas}

Há imagens que identificam os setores populares com metáforas da natureza, revelando uma visão naturalizada, pré-humana: ver os setores populares como selvagens, bestializados, desarraigados, embrutecidos, 
instintivos, gregários... Esta visão é reforçada por metáforas tiradas da patologia: fala-se da ignorância popular e do analfabetismo como doenças, da violência popular como chaga social. Até as lutas e movimentos populares são vistos como anomalias, como fenômenos mórbidos que ameaçam o organismo social.

Estas visões naturalizadas, biologizadas e patológicas dos setores populares ainda estão muito arraigadas e orientam o pensamento, as análises e a ação, as políticas, programas e campanhas de educação, de saúde e de assistência. Estas metáforas afirmam que assim como os acidentes naturais e as doenças põem em perigo o corpo humano, os setores populares e sua irracionalidade e ignorância póem em perigo o corpo social, político, cultural e moral. As campanhas e políticas passam a ter um caráter preventivo para evitar que o povo contamine o corpo social sadio. Será necessário pesquisar como estamos em tempos em que estas imagens rebrotam com força tanto diante das múltiplas manifestações - "oleadas - de violência popular", como diante dos movimentos sociais dos campos e periferias urbanas. A mídia fala das "avalanches imprevisíveis de reivindicações dos coletivos populares" - dos sem-terra, sem-teto, sem-universidade, sem-trabalho... Será necessário estarmos atentos às "novas" velhas imagens repostas na mídia, nas políticas e campanhas e até nas análises sobre as manifestações populares.

Estas imagens persistentes repõem na sociedade significados, pensamentos, concepções e formas de ação em relação aos setores populares. Os campos da ação social, saúde, educação e assistência são os mais afetados por esta reposição permanente de imaginários. As culturas dos profissionais destes campos são especialmente afetadas pela reposição persistente destas imagens, situação que o avanço na consciência profissional não tem conseguido superar.

\section{De carentes sociais a desqualificados morais}

Há outras imagens que são persistentes e passam por processos de brutal ressignificação. Por exemplo, ver o povo como pobre, atrasado, subdesenvolvido e desqualificado. Estes traços, que tinham como referentes situações sociais, carências sociais e econômicas, estão sendo redefinidos por significados de carências morais. Com essa visão, são representados os setores populares como pobres de valores, desqualificados 
morais, incivilizados, violentos, desordeiros, ameaçadores, perigosos. As imagens do povo que a literatura, as histórias e narrativas passavam em décadas ainda recentes eram de um povo ignorante, mas ordeiro, atrasado, mas pacífico, pobre, mas honesto, desqualificado, mas esforçado, distante, mas confiável... Essa visão dos setores populares marcou as políticas, programas e campanhas para o povo, na educação, saúde, cultura, promoção social. Políticas invocadas pelo integracionismo, pelo paternalismo e assistencialismo, assim como por campanhas pela elevação cultural e em defesa de processos civilizatórios e ilustradores do povo.

Campanhas e ações de educação popular até progressistas partiam dessa visão ordeira, pacífica, honesta, esforçada e confiável dos setores populares. Uma visão um tanto infantilizada, pura, idealizada, angelical do popular, que levou a ações educativas em defesa e preservação da pureza dessa "infância - povo"; uma visão protecionista e defensiva, preservacionista dos valores, da cultura e dos saberes inocentes do povo. Os tratos pedagógicos aprendidos com a infância idealizada foram transpostos ao povo infantilizado.

A burguesia agrária, os políticos, as elites e até as camadas médias nunca tiveram uma visão tão romântica dos setores populares, nem dos campos, nem das periferias urbanas. Tiveram posturas desconfiadas que agora rebrotam diante das ameaças que vêm dos setores populares em formas múltiplas de resistências, de protestos e de lutas organizadas.

\section{E quando as autoimagens do próprio povo mudam?}

O dado mais relevante é que estamos em outros tempos, não apenas quanto às imagens com que são vistos e representados os setores populares, mas em outros tempos em relação a como os próprios setores populares se identificam, se representam e se mostram à sociedade. Quando o povo muda suas autoimagens e suas práticas, as imagens sociais sobre eles são quebradas e forçadas a mudar. Estamos em tempos em que as imagens e significados preconceituosos sobre o povo são forçados a se rever, na mídia, na intelectualidade, nas ciências sociais, na educação, na saúde e na cultura dos profissionais destas áreas.

Até que ponto as mudanças nas autoimagens dos setores populares conseguirão reeducar nossa cultura política tão preconceituosa? Esta redefinição das autoimagens do povo nos coloca perante 
outra dinâmica educativa. Ações coletivas de reação à segregação e à opressão têm uma longa história entre nós. Não são novas. De sua dinâmica pedagógica se alimentou o movimento de educação popular. $\mathrm{Na}$ medida em que estas ações coletivas populares se organizaram e se tornaram mais visíveis na sociedade, vêm provocando uma nova dinâmica político-cultural.

Estamos em outro momento, não mais de pensar em ações de educação e saúde, em pedagogias para o povo, mas estamos em tempos de nos deixar reeducar pelas autoimagens, práticas, resistências coletivas e pelos movimentos populares, de reconhecer nos movimentos sociais populares os "novos" pedagogos da sociedade, da cultura política, social e pedagógica.

Talvez o tempo não seja tanto de voltarmos à história do movimento de educação popular e saúde para reaprendermos com sua história, mas de entender as lições que vêm dos próprios movimentos sociais populares e da pluralidade de ações coletivas cada vez mais organizadas e mais visíveis. Os coletivos que eram pensados como destinatários da educação popular e de saúde passaram a sujeitos coletivos de tensos e incômodos processos de autoeducação.

É esclarecedor que as elites políticas e até intelectuais tenham mais medo dos novos sujeitos coletivos, pedagógicos, dos movimentos sociais populares, do que do movimento de educação popular e saúde. Nós, intelectuais, e nossos movimentos sempre fomos mais confiáveis às elites do que os movimentos vindos do próprio povo. As desconfianças em relação ao povo sempre foram maiores do que em relação aos intelectuais, educadores e profissionais de saúde comprometidos com o povo. Neste quadro tão diferente daquele dos anos de 1960, quando se articula o movimento de educação popular, que sentido poderão ter políticas, ações, iniciativas de articulação entre educação popular e saúde? Quais os rumos para a educação popular? Quais são as novas autoimagens de educador popular?

Nestes novos tempos, de nova presença política e cultural dos setores populares, não cabem mais imaginários românticos, infantilizados, nem pacíficos e ordeiros e, menos ainda, submissos. Com que imaginários equacionar políticas, campanhas, ações e compromissos educativos? A tendência pode ser nos deixar contaminar pelos novos imaginários que estão postos na sociedade e na cultura política, diante 
da ousadia dos setores populares de se organizarem e de se tornarem visíveis na arena política. As imagens ameaçadoras e desconfiadas estão se impondo. A demonização dos movimentos populares está orquestrada, o medo coletivo diante dos "violentos" está se espalhando. Que papel caberia ao movimento de educação popular e saúde neste novo quadro? Desconstruir esses imaginários será muito mais complexo e tenso do que foi afirmar, em décadas recentes, que o povo tem saberes, culturas, valores, quando as imagens bondosas, românticas e infantilizadas tinham um certo consenso social. Lembremos que naquela época até as elites contrapunham a inocência e bondade populares às ideologias externas desestabilizadoras que os militantes tentavam "incutir ao povo despolitizado". A ameaça era posta nos intelectuais e educadores e nas suas ideologias importadas, não nos setores populares. Hoje, o medo vem da resistência e da ousadia que manifestam os próprios setores populares organizados, não mais identificados como ordeiros e ingênuos. Estas mudanças exigem outras posturas da educação popular e saúde.

Continuar reafirmando aqueles valores e virtudes populares pode estar fora de foco. Será necessário encontrar o pedagógico nas resistências, inconformismos, rebeldias e até "violências"; nas lutas coletivas e nas frentes e campos dessas lutas por terra, teto, território, trabalho, vida, saúde, sobrevivência, memória e identidade, entre outras. Sobretudo, será necessário rever a visão que o próprio movimento de educação e saúde construiu em relação aos setores populares, ao longo das últimas quatro décadas; passar a reconhecer nos setores populares organizados e seus movimentos os novos educadores; entender e reconhecer a pedagogia dos movimentos, suas concepções pedagógicas, suas didáticas e seus processos de formação.

\section{Imaginários em confronto}

Uma das exigências deste momento pode ser pesquisar e tentar entender melhor, em diálogo com as ações coletivas e com os movimentos populares, que autoimagens estes estão construindo, com que traços as constroem, qual sua concepção político-educativa. A partir daí, poderemos confrontá-las com nossas concepções e com as concepções e práticas do movimento de educação popular e saúde. Poderemos aprender com os movimentos sociais como se contrapõem às imagens 
negativas com que a sociedade tenta reagir e contrapor a sua afirmação de autoimagens positivas.

É importante perceber que, de um lado e de outro, se usam expressões de guerra, de confronto explícito. Os movimentos populares são pichados como ameaçadores da ordem, subversivos, e eles mesmos se vêm como combatentes de um conflito político, ideológico e pedagógico. Neste novo contexto, não passa pelas elites a ideia de educar os coletivos populares, mas de derrotá-los. Esta visão bélica levará ao redimensionamento do caráter ameaçador das suas lutas e resistências para poder justificar posturas de condenação, e não de educação ou mesmo de integração. Fazer das lutas dos movimentos populares um problema de ordem pública levará a despolitizá-las e situá-las no campo da repressão policial e das aplicações das leis. Tudo bem distante do equacionamento pedagógico que a educação popular sempre deu. Esta visão bélica, em que a mídia e as elites tentam enquadrar as representações dos coletivos populares, está criando uma contraposição entre estes coletivos e a sociedade, até intelectuais e universidades. A revista Veja (outubro de 2009) destaca a ousadia do MST em ocupar a universidade. $\mathrm{Na}$ mesma direção, intelectuais, em manifestos e livros, alertam para a ousadia dos coletivos negros em defender ações afirmativas de acesso e permanência nas universidades.

Esta contraposição entre coletivos populares das cidades e do campo e setores da sociedade desloca a tensão do campo político pedagógico para confrontá-lo na oposição entre ordem e caos, entre barbárie e civilização, entre as normas e sua transgressão. Giros estes no imaginário social sobre o povo que têm consequências para as políticas e tratos dos setores populares e que obrigam a educação popular a distanciar-se dos tratos a que tinha se habilitado desde suas origens. As imagens e metáforas de povo ordeiro, educável, integrável e até conscientizável e politizável para integração na ordem ficam distantes. Os setores populares passam a ser vistos como ameaça, não só por suas lutas organizadas, mas por suas resistências e sua presença nas ruas e até por suas indisciplinas nas escolas; pelo envolvimento em redes de tráfego e tantos sintomas de "degradação" atribuídos aos setores populares e até as suas crianças e jovens.

Passaram-se os tempos em que se ocultava a visão dos setores populares, sobretudo as formas reais de viver a infância popular sob metáforas e máscaras de inocência e bondade. Estamos em tempo de trocar 
as metáforas pelo ataque direto e até pela eliminação de adolescentes e jovens e de militantes populares. Atacar e eliminar sem máscaras. A educação popular e de saúde não poderá apegar-se a imaginários, nem a metáforas, nem a cultivar novas máscaras que ocultem o real. A questão é mais radical: como se contrapor não apenas a imagens orquestradas de violentos e ameaçadores, mas a práticas eliminatórias? Como se contrapor ao medo que se espalha contra os movimentos em prol da terra, teto, universidade, saúde, vida, território, dignidade? Sem dúvida, não será como antes, com ações educativas isoladas, nem com pedagogias conscientizadoras. Consciência popular nunca faltou. Os movimentos populares e as ações coletivas educam e canalizam esta consciência e a politizam. Como somar com estes processos para alargar a consciência popular?

Os coletivos populares repolitizam e radicalizam a educação popular

As perspectivas que os coletivos populares apontam vão no sentido de não situar suas lutas no plano policial, da segurança e da manutenção da ordem, mas no campo dos direitos, da política. Situados no plano da segurança e da ordem, não haverá espaço para propostas pedagógicas. Só haverá espaços situados na radicalização política. Os movimentos populares, politizando suas lutas coletivas, repolitizam as dimensões pedagógicas, os processos educativos que alimentaram o movimento de educação popular e saúde. Permitem o reencontro entre política e educação que está na origem deste movimento.

Falamos em repolitizar o movimento de educação popular que nasceu em tempos tensos, de conscientização política. Nasceu politizado e para conscientizar um povo ainda supostamente inconsciente e despolitizado. O quadro hoje é outro, mesmo que nem tudo seja "novo", as tensões políticas são outras. Os próprios coletivos populares agem como sujeitos políticos em estado de confronto. Neste quadro, a educação popular e de saúde é levada a se repolitizar e se radicalizar.

Neste contexto tão politizado, a sociedade e até a mídia não mais colocarão o trato no campo pedagógico, mas no da segurança e da manutenção da ordem. As soluções serão menos pedagógicas do que policiais - eliminar lideranças dos movimentos -, ou soluçôes legalistas - rebaixar a idade penal para conter a violência infanto-juvenil. 
Os movimentos populares reagem as estas tentativas conservadoras de despolitização de suas ações, inventam gestos para chocar a cultura política e abrem espaços para explorar suas dimensóes pedagógicas. Talvez a colocação mais correta seja como a educação popular e a saúde deverão se aproximar da nova dinâmica educativa provocada pelos novos educadores: os coletivos populares em movimentos. Quais os novos vínculos entre educação popular e saúde e esta dinâmica educativa? Aí encontra seu sentido o tema "educação, saúde, equidade e justiça social".

\section{Direitos coletivos, equidade e justiça}

Os movimentos populares repolitizam e radicalizam a pedagogia popular, na medida em que repóem suas lutas no campo do direito. Ao afirmarem-se sujeitos de direitos, vinculam as políticas sociais com a igualdade, a justiça e a equidade. Não mais com a inclusão excludente. Fazem avançar uma conformação do povo como sujeito de direitos.

Pontuemos alguns traços dessa nova dinâmica de conformação do popular.

\section{Setores populares com traços mais definidos}

A educação popular trabalhou com uma concepção de povo um tanto ampla, sem contornos definidos: povo, massas, setores populares, excluídos, marginalizados, oprimidos... Os processos pelos quais o povo foi passando nas últimas décadas foram desconstruindo essa visão indefinida e diversos coletivos populares foram mostrando suas identidades mais definidas em suas açôes coletivas, deixando para trás a categoria amorfa de povo, massas.

Esse processo traz questões para a educação popular e de saúde. Até onde acompanharam essas transformaçōes na conformação de "outro" povo? Ainda se trabalha com referências amplas de saberes, de culturas, valores e práticas de educação e saúde?

As questóes mais instigantes podem ser: em que processos de fora e de dentro foram se dando essas novas configurações do popular? Que novos valores, saberes, culturas e identidades foram se constituindo nesses processos? Que demandas vêm dessa nova configuração do popular para a educação e a saúde? Que outras teorias e práticas são 
Educação popular, saúde, equidade e justiça social

exigidas? Como a educação popular e a saúde vêm contribuindo na conformação desse "outro" povo?

\section{O avanço da consciência dos direitos}

A educação popular tem que partir da um dado novo: o avanço $\mathrm{da}$ consciência dos direitos nos setores populares. Os coletivos organizados em movimentos e em ações coletivas são a expressão política desse avanço da consciência dos direitos nos setores populares. Esse dado traz uma referência nova para pensar a educação popular, a saúde e as políticas sociais. Quando a referência era um povo sem consciência, despolitizado, submisso aos mecanismos do poder político, econômico, cultural, a educação popular teve como horizonte a conscientização e politização. Na medida em que a consciência dos direitos avança entre os setores populares, os horizontes da educação popular e da saúde terão que somar com esses avanços, explicitar seus significados, politizar e trabalhar os processos pedagógicos em que essa consciência dos direitos é produzida e afirmada.

Os processos educativos terão que ser buscados nas vivências, tensões e confrontos colocados na sociedade em defesa de direitos. Em que medida essas novas vivências populares, reivindicando e lutando por direitos, educam? Quais as dimensões pedagógicas desses processos e vivências? Que indagações trazem para as concepções de educação popular em saúde, por exemplo? E para as tradicionais didáticas e métodos de educação popular? Para Paulo Freire, a experiência da opressão é pedagógica, o vivenciar e saber-se oprimido conscientiza, politiza e humaniza. E o vivenciar, saber-se e lutar por direitos à terra, ao teto, à educação, à saúde... Que novas dimensões conscientizam, politizam e humanizam?

Que os coletivos populares se saibam sujeitos de direito à vida, à saúde exige outras formas de vincular educação popular e saúde do que quando a saúde era vista como uma dádiva dos governos benevolentes e de educadores e profissionais comprometidos. Situadas no referente dos direitos, as questões centrais não serão apenas que saberes de saúde o povo tem, como incorporar esses valores no conhecimento científico, como fazer dos setores populares co-participes em programas de saúde... As questôes terão que ser outras: que dimensões adquirem a saúde, as doenças, a precarização da vida, do trabalho, das condições de 
viver, quando a vida e a saúde são reivindicadas como direito? O que é ser um profissional de direitos? Que saberes sobre os direitos e sua história de afirmação-negação terá de dominar um profissional-educador de saúde popular? Idênticas indagações chegarão às políticas, cursos e ações de saúde, quando o referente ético-político passar a ser o direito popular à saúde e ao conjunto dos direitos sociais, culturais, humanos.

\section{O emaranhado de direitos}

Chegamos a um ponto nuclear: o entrelaçamento entre o conjunto dos direitos tanto em sua negação, quanto em sua garantia. $\mathrm{O}$ direito ao conhecimento, à cultura, à educação ou à saúde e à vida não avança separando cada um desses direitos da negação ou garantia do conjunto dos direitos humanos. Nem avança separando-os da condição de silenciamento, marginalização, segregação histórica e persistente a que foram e são submetidos os setores populares. Esse atrelamento estava claro para o movimento de educação popular e é repolitizado pelos coletivos populares em movimento. Este terá que ser um dos traços mais fortes da educação popular e de saúde: equacionar ações, defender políticas que façam avançar a garantia dos direitos fundamentais na diversidade de suas articulações com o direito à educação e à saúde. À vida.

\section{A centralidade do direito à vida}

Nesta direção, os coletivos populares orientam suas lutas: garantir os direitos que estão na base de seu direito à vida. Vem a vida de suas populações, de seus filhos ou dos idosos articulada à garantia do direito ao território, às florestas, à terra, à agricultura familiar, à tradição e às culturas coletivas, ao trabalho, ao teto, à sobrevivência... É extremamente educativo para a sociedade e para nós, intelectuais-educadores, que tanto valorizamos a consciência ilustrada, desmaterializada, o quanto os coletivos populares lutam pela vida e por toda a base material e cultural de que depende a vida e, consequentemente, a saúde.

É como se os coletivos populares apontassem uma direção de sentido para a educação popular e de saúde: o direito primeiro à vida e as bases que a garantem. Como avançar nessa direção de sentido apontada pelos coletivos populares? Que força pedagógica tem o direito à 
vida nos setores populares submetidos a formas tão precarizadas de viver? Que valor dão à vida, à saúde, e como esse valor primeiro dá sentido a seu trabalho, a suas formas de produção e a suas lutas? Terra é mais do que terra, terra é fonte de vida, "trabalho e saúde". Que peso dar aos processos de educação popular à vida, à terra, à floresta, ao território enquanto valor-referência?

\section{Coletivos lutando por direitos coletivos}

Outro traço de indagação para a educação popular e de saúde: os coletivos populares se organizam como coletivos em lutas por direitos coletivos. Os direitos não são de cada um, mas do coletivo. O direito à vida, à terra, à saúde, à moradia, ao território, ao trabalho, à tradição, à memória ou à identidade de coletivos. Essa dimensão coletiva dos direitos se choca com visóes e tratos individualizados, obrigando-nos a repensar os direitos e as formas de garanti-los em coletivo. Choca-se com o trato individualizado do direito à saúde, à educação, à escola, à propriedade, à moradia e ao trabalho. Direitos individuais, atendimentos individualizados.

Mais ainda, os coletivos populares, em sua diversidade, se sabem um produto de múltiplas açôes e políticas negativas enquanto coletivos. Por isso, reivindicam açôes e políticas afirmativas para seus coletivos. Como coletivos, foram segregados e, como tais, lutam por se afirmar como sujeito de direitos.

As consequências para a educação popular e de saúde são instigantes: que peso pedagógico encontrar nos sofrimentos coletivos do passado e do presente? Que açōes e que políticas afirmativas inventar e exigir do Estado e de suas instituiçôes? Por exemplo, a área de saúde terá que pensar em formar profissionais com saberes mais focados, mais afirmativos para a saúde popular? Está se avançando nessa direção em áreas como na formação de educadores do campo, de agrônomos e de profissionais da saúde para garantir os direitos dos povos do campo. Na mesma direção de políticas afirmativas, existem cursos específicos para preparar profissionais para a especificidade dos povos indígenas, quilombolas, negros... Os setores populares sabem que as doenças, a desnutrição, o não-atendimento, a escassez de serviços e de profissionais são fruto de sua condição coletiva de povos do campo, indígenas, favelados, marginalizados. Fruto de desnutrição coletiva, 
insalubridade coletiva, trabalho extenuante coletivo, exploração coletiva de seus corpos desde criança. E que peso dar a esta consciência coletiva nos projetos e nas ações de educação-saúde?

Por outro lado, os saberes, os valores e a cultura dos setores populares sobre a vida, a saúde, o trabalho... são produzidos em processos coletivos de socialização, sociabilidade, de formas de produção, de transmissão e aprendizagens coletivas, de mobilizaçóes coletivas. As práticas de saúde têm um caráter coletivo na tradição familiar, camponesa, indígena, comunitária... Estas dimensões coletivas, tão enfatizadas nas lutas, mobilizaçôes e na consciência da dimensão coletiva da negação e da afirmação de direitos, são algumas das dimensões centrais a serem levadas em conta nas políticas e ações de educação popular e saúde e na formação dos profissionais-educadores.

Esta diversidade de açôes populares coletivas tem um horizonte comum: lutam por outro projeto de sociedade orientado em outros valores: igualdade na diversidade, equidade, justiça. Os movimentos sociais incomodam por não lutarem apenas pela inclusão-excludente no projeto de sociedade que aí está, mas por lutarem por outro projeto de sociedade, por outro projeto de campo, de cidade, de sistema educacional, de sistema de saúde...

Frequentemente, os ideários de educação e saúde, quando pensavam no povo, tinham como horizonte incluí-lo nos benefícios do projeto de sociedade que está posto. Se este fosse o horizonte dos movimentos sociais populares, estes não incomodariam às elites, aos intelectuais, às políticas e às universidades. $\mathrm{O}$ incômodo vem de não aceitarem este convite à inclusão e lutarem por outros valores que orientem outro projeto de sociedade. Incomodam por questionarem valores de propriedade, de igualdade, de inclusão, de acesso ao sistema de educação e saúde etc. O embate é posto no plano dos valores que vêm legitimando o projeto de sociedade vigente.

$\mathrm{Na}$ tradição da educação popular e de saúde, se deu mais relevância ao reconhecimento e trato dos saberes populares do que aos valores. O confronto vem se dando no campo dos valores, um confronto poliético por outro projeto de sociedade, legitimado em outros valores.

Nesses traços comuns na conformação do povo e dos diversos setores como sujeitos de direitos, encontra todo o significado político 
Educação popular, saúde, equidade e justiça social

vincular educação popular, saúde, equidade e justiça social. Tais vínculos repolitizam e radicalizam o movimento histórico da educação popular e da saúde popular.

Recebido em abril de 2008 e aprovado em maio de 2009. 